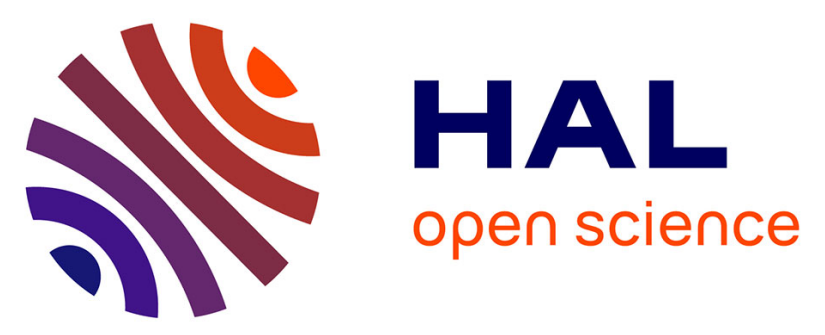

\title{
Formation of Haloacetonitriles, Haloacetamides, and Nitrogenous Heterocyclic Byproducts by Chloramination of Phenolic Compounds
}

\author{
Maolida Nihemaiti, Julien Le Roux, Christiane Hoppe-Jones, David A.
} Reckhow, Jean-Philippe Croué

\section{To cite this version:}

Maolida Nihemaiti, Julien Le Roux, Christiane Hoppe-Jones, David A. Reckhow, Jean-Philippe Croué. Formation of Haloacetonitriles, Haloacetamides, and Nitrogenous Heterocyclic Byproducts by Chloramination of Phenolic Compounds. Environmental Science and Technology, 2017, 51 (1), pp.655 663. 10.1021/acs.est.6b04819 . hal-01425762

\section{HAL Id: hal-01425762 \\ https://hal-enpc.archives-ouvertes.fr/hal-01425762}

Submitted on 19 Apr 2018

HAL is a multi-disciplinary open access archive for the deposit and dissemination of scientific research documents, whether they are published or not. The documents may come from teaching and research institutions in France or abroad, or from public or private research centers.
L'archive ouverte pluridisciplinaire HAL, est destinée au dépôt et à la diffusion de documents scientifiques de niveau recherche, publiés ou non, émanant des établissements d'enseignement et de recherche français ou étrangers, des laboratoires publics ou privés. 


\title{
Formation of haloacetonitriles, haloacetamides and nitrogenous heterocyclic by-products by chloramination of phenolic compounds
}

\author{
Maolida Nihemaiti a, Julien Le Roux b, Christiane Hoppe-Jones c, David A. \\ Reckhow $^{d}$, Jean-Philippe Croué ${ }^{\text {a,* }}$ \\ a Curtin Water Quality Research Centre, Department ofChemistry, Curtin University, \\ GPO Box U1987, Perth, WA 6845, Australia
b LEESU (UMR MA 102), Université Paris-Est - AgroParisTech, 61 avenue du Général de 8 Gaulle, 94010 Créteil cedex, France

${ }^{c}$ Department of Chemical and Environmental Engineering, The University of Arizona, P.O. 10 Box 210011, Tucson, AZ, United States

d Department of Civil and Environmental Engineering, University of Massachusetts Amherst, 18 Marston Hall, 130 Natural Resources Rd., Amherst, MA 01003-9293, United States

\section{Corresponding Author}

*Tel.:+61(0)892669793; fax: +61(0)892662300; e-mail: jean-philippe.croue@curtin.edu.au

\begin{abstract}
The potential formation of nitrogenous disinfection by-products (N-DBPs) was investigated from the chloramination of nitrogenous and non-nitrogenous aromatic compounds. All molecules led to the formation of known N-DBPs (e.g., dichloroacetonitrile, dichloroacetamide) with various production yields. Resorcinol, a major precursor of chloroform, also formed di-/tri-chloroacetonitrile, di-/trichloroacetamide, and haloacetic acids, indicating that it is a precursor of both N-DBPs and carbonaceous DBPs (C-DBPs) upon chloramination. More detailed experiments were conducted on resorcinol to understand N-DBPs formation mechanisms and to identify reaction intermediates. Based on the accurate mass from high resolution Quadrupole Time-of-Flight GC-MS (GC-QTOF) and fragmentation patterns from electronic impact and positive chemical ionization modes, several products were tentatively identified as nitrogenous heterocyclic compounds (e.g., 3-chloro-5-hydroxy1H-pyrrole-2-one with dichloromethyl group, 3-chloro-2,5-pyrroledione). These products were structurally similar to the heterocyclic compounds formed during chlorination, such as the highly
\end{abstract}


mutagenic MX (3-chloro-4-(dichloromethyl)-5-hydroxy-2(5H)-furanone) or halogenated pyrroles. To our knowledge, this is the first time that the formation of halogenated nitrogenous heterocyclic compounds is reported from chloramination process. The formation of these nitrogenous by-products during chloramination might be of concern considering their potential toxicity.

\section{ABSTRACT ART}
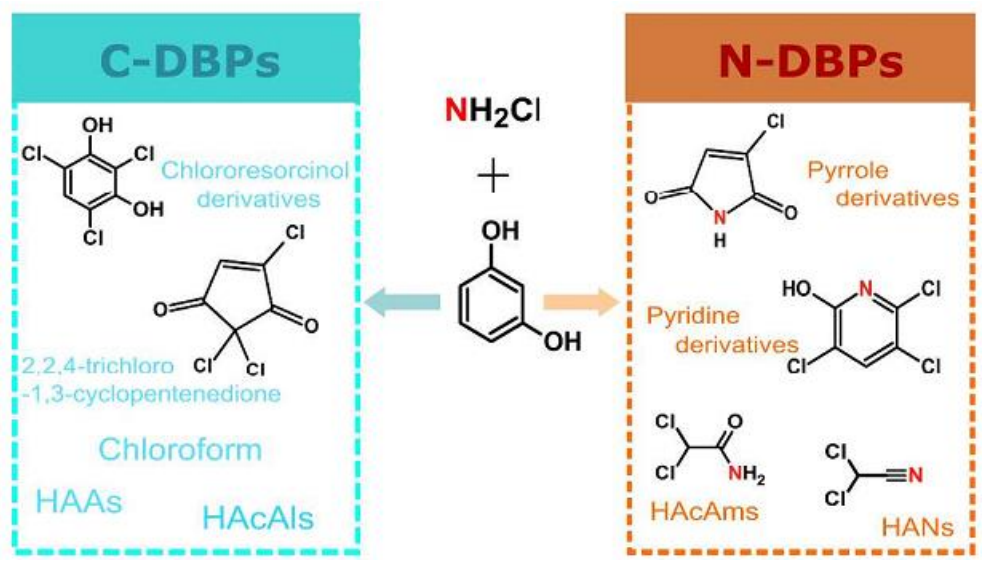

\section{INTRODUCTION}

As an alternative to chlorine, monochloramine $\left(\mathrm{NH}_{2} \mathrm{Cl}\right)$ is often used as a secondary disinfectant to obtain a more stable residual in distribution systems (Seidel et al., 2005). Chloramines generally form less trihalomethanes (THMs), haloacetic acids (HAAs) and total organic halogen (TOX) than free chlorine. However, the percentage of unknown TOX produced from chloramines is higher than that from free chlorine (Hua et al., 2007).

During chloramination, $\mathrm{NH}_{2} \mathrm{Cl}$ can be an additional source of nitrogen and produce halogenated nitrogenous disinfection by-products (N-DBPs). N-DBPs, including haloacetonitriles (HANs) and haloacetamides (HAcAms), generally form in lower amounts than regulated DBPs (i.e., THMs and HAAs). It has been proposed that the mass of HANs represents around $10 \%$ of the THMs (Krasner Stuart et al., 1989; Oliver, 1983) whereas HAcAms formation was reported to be approximately 10 times lower than HAAs (Krasner et al., 2006). Regardless of their relatively low occurrence, HANs and HAcAms have been a growing health risk concern over the past decades because of their high toxicity (Muellner et al., 2007; Plewa et al., 2004).

Nitrogen-containing organic compounds (e.g., amino acids, pyrroles and pyrimidines) are ubiquitous in surface water (Westerhoff et al., 2002) and have been associated with the formation of N-DBPs (Bond et al., 2011). Wastewater effluents and algal organic matter, which are enriched in organic nitrogen, enhance N-DBPs formation during drinking water treatment process (Dotson et al., 2009). It 
was recently reported that antibiotic chloramphenicols may contribute to the formation of HAcAms in heavily wastewater-impacted waters (Chu et al., 2016).

Most of the previous studies exploring the sources of nitrogen in N-DBPs focused on chloramination of nitrogenous model compounds (e.g., amino acids) or matrices enriched in nitrogen moieties (e.g., algal organic matter) by the application of isotopically labeled monochloramine (i.e., ${ }^{15} \mathrm{NH}_{2} \mathrm{Cl}$ ). Inorganic nitrogen incorporation into dichloroacetonitrile (DCAN) and dichloroacetamide (DCAcAm) has been reported during chloramination of wastewater effluents, algal extracellular organic matter, humic substances and free amino acids (i.e., aspartic acid and asparagine) (Huang et al., 2012). ${ }^{15} \mathrm{~N}$-DCAN percentages in total DCAN were found to be $78 \%$ and $92 \%$ by chloramination of tryptophan and Suwannee River NOM, respectively (Yang et al., 2010). More than 70\% of DCAN originated from monochloramine during chloramination of NOM isolates (Huang et al., 2012), indicating that high amounts of inorganic nitrogen (i.e., Monochloramine) can be incorporated into organic structure.

Only few studies are available on N-DBPs formation from non-nitrogenous precursors. Formaldehyde reacts with $\mathrm{NH}_{2} \mathrm{Cl}$ to form cyanogen chloride (Pedersen et al., 1999). Chloroacetonitrile and N,2-dichloroacetamide formation was found from chloramination of chloroacetaldehyde (Kimura et al., 2013). Recent studies on chloramination of lignin phenols and low-molecular weight organic acids have reported the formation of DCAN, DCAcAm and trichloroacetamide (TCAcAm) through chloramine-nitrogen incorporation (Chu et al., 2016; Chuang et al., 2015; Hua et al., 2014).

Previous studies indicated that non-nitrogenous precursors can produce N-DBPs via inorganic nitrogen incorporation. However limited information is available on the nature of these N-DBPs precursors as well as the chloramine-nitrogen incorporation mechanism. Recent results showed that organic matter isolates enriched in aromatic moieties (i.e., high SUVA value) produced more N-DBPs by chloramine-nitrogen incorporation as compared to low-aromatic-content organic matter (Le Roux et al., 2016). In addition, chloramination of aromatic model compounds (i.e., phenol and resorcinol) formed more DCAN and DCAcAm than amino acids (e.g., tyrosine, aspartic acid), which were previously considered as important precursors of N-DBPs.

Meta-dihydroxybenzene structures were proposed as main reactive sites of NOM for the formation of THMs upon chlorination (Norwood et al., 1980; Rook, 1977). 1,3-hydroxybenzene (resorcinol) has been extensively studied as a model compound and is a major precursor of chloroform (TCM) during chlorination (Boyce et al., 1983; Norwood et al., 1980; Rook, 1980). The reaction of resorcinol with monochloramine follows a similar mechanism to chlorination, involving aromatic ring-substitution, oxidation, hydrolysis and decarboxylation reactions (Heasley et al., 1999). However, the reactions involving the formation of N-DBPs from resorcinol by incorporation of nitrogen from monochloramine have not been investigated yet.

The objective of this study was to investigate the formation of HANs and HAcAms from chloramination of resorcinol in comparison with TCM and HAAs formation and to elucidate their 
formation mechanisms through the identification of intermediate products. Effects of monochloramine dose, reaction time, and $\mathrm{pH}$ on by-products formation were examined. GC-MS/MS and high resolution GC-QTOF full scan analysis were conducted for the identification of unknown products.

\section{EXPERIMENTAL SECTION}

Materials. All chemicals were of analytical grade or higher and were used as received without further purification. Milli-Q water (18.2 M $\Omega . c m$, Millipore) was used for all experiments. Resorcinol $(\geq 99.0 \%)$ and other model compounds were purchased from Sigma-Aldrich (Table S1). Sodium hypochlorite (5.65-6\%, Fisher Scientific) and ammonium chloride (99.6\%, Acros Organics) were used for monochloramine preparation. ${ }^{15} \mathrm{~N}$ - labeled ammonium chloride was obtained from Sigma-Aldrich (98\%). Sodium thiosulfate (Fisher Scientific) was applied to quench residual oxidant. A trihalomethanes (THM) calibration mix, a mixed standard (EPA 551B Halogenated Volatiles Mix) containing haloacetonitriles (HANs), and a mixed standard (EPA 552.2 Methyl Ester Calibration Mix) containing 9 haloacetic acids (HAAs) were supplied from Supelco (Sigma-Aldrich). Chloro-, dichloro- and trichloroacetamide were obtained from Sigma-Aldrich. Decafluorobiphenyl (99\%, Sigma-Aldrich, Supelco) was used as a surrogate standard. 2-bromopropionic acid (Fluka Analytical) was used as a surrogate for HAAs extraction and analysis. Fisher Scientific Methyl tert-butyl ether (MTBE) and ethyl acetate (> 99\%) were used for DBP extractions.

Experimental procedures. Experiments were conducted at room temperature $\left(22 \pm 1^{\circ} \mathrm{C}\right)$ in headspace-free amber glass bottles (individual bottle per contact time). Preformed monochloramine and ${ }^{15} \mathrm{~N}$-labeled monochloramine stock solutions were daily prepared by dissolving ammonium chloride or ${ }^{15} \mathrm{~N}$-labeled ammonium chloride, respectively, in Milli-Q water adjusted to $\mathrm{pH} 8.5$ with sodium hydroxide. Sodium hypochlorite was then slowly added to the rapidly stirred solution $(\mathrm{N}: \mathrm{Cl}$ molar ratio of 1.2:1). Initial $\mathrm{NH}_{2} \mathrm{Cl}$ and $\mathrm{NHCl}_{2}$ concentrations were spectrophotometrically measured at 245 and $295 \mathrm{~nm}$ (Schreiber et al., 2005). Predetermined volumes of monochloramine and each model compound stock solution were injected into $65 \mathrm{~mL}$ of $10 \mathrm{mM}$ acetate $(\mathrm{pH}=4.0-5.5)$, phosphate $(\mathrm{pH}=7.0-8.0)$ or carbonate $(\mathrm{pH}=10)$ buffer to get the desired initial concentrations (monochloramine:model compound molar ratio of 5.6 or 11.2). The concentration of residual oxidant was iodometrically determined (Eaton et al., 1995). Residual monochloramine was quenched with a slight excess of sodium thiosulfate. Samples were extracted immediately after quenching to avoid any loss of by-products.

GC-MS and GC-QTOF-MS/MS Analysis. TCM and two HANs (dichloroacetonitrile, trichloroacetonitrile) were analysed after liquid-liquid extraction following EPA Method 551. Three HAcAms (chloroacetamide, dichloroacetamide, trichloroacetamide) were analysed following the 
same protocol that was applied for HANs; however, the extraction solvent MTBE was replaced by ethyl acetate since it was shown to improve the recovery of HAcAms (Chu and Gao, 2009). HAAs were extracted and analysed following the EPA Method 552.2, which is based on a liquid-liquid extraction with MTBE in acidic condition followed by derivatization to methyl esters using acidic methanol. All DBPs were quantified using a gas chromatograph (Agilent 7890A) coupled with a mass spectrometer (Agilent 5975C, GC-MSD). Since ${ }^{15} \mathrm{~N}$-labeled DBPs are not commercially available, their concentrations were determined using ${ }^{14} \mathrm{~N}$-DBPs standards, based on the assumption that ${ }^{15} \mathrm{~N}$ DBPs and ${ }^{14} \mathrm{~N}$-DBPs have a similar MS response (Huang et al., 2012). DBPs were separated on a DB$1701(30 \mathrm{~m} \times 250 \mu \mathrm{m} \times 0.25 \mu \mathrm{m})$ capillary column.

In order to identify unknown by-products, full scan analysis in electronic impact (EI) and positive chemical ionization (PCI, using methane as reagent gas) modes were performed on MTBE extracts at various reaction times. Two different GC-MS systems were used for full scan analysis: an Agilent 5975C GC-MSD and an Agilent 7200 Accurate-Mass Quadrupole Time-of-Flight (GC-QTOF). MS/MS analysis at three different collision energies (i.e., $20 \mathrm{eV}, 40 \mathrm{eV}$ and $60 \mathrm{eV}$ ) were performed on GC-QTOF for all main peaks detected. Agilent MassHunter Qualitative analysis B.07.00 was used for deconvolution of data from GC-QTOF. The column used for GC-MSD was a DB-1701 $(30 \mathrm{~m} \times 250$ $\mu \mathrm{m} \times 0.25 \mu \mathrm{m})$ or a ZB-5MS $(30 \mathrm{~m} \times 250 \mu \mathrm{m} \times 1 \mu \mathrm{m})$. GC separation on GC-QTOF was performed with a DB-5MS UI column $(30 \mathrm{~m} \times 0.25 \mathrm{~mm} \times 0.25 \mu \mathrm{m})$.

Details on quantification of DBPs and full scan analysis of unknown by-products are provided in Text S1.

\section{RESULTS AND DISCUSSION}

N-DBPs Formation from Model Aromatic Compounds. Preliminary experiments were conducted at $\mathrm{pH} 7$ (10 mM phosphate buffer) for $72 \mathrm{~h}$ to investigate the formation potential of DCAN and DCAcAm from several aromatic compounds $(250 \mu \mathrm{M})$ during chloramination $(1.4 \mathrm{mM}) .{ }^{15} \mathrm{NH}_{2} \mathrm{Cl}$ was applied to nitrogenous model compounds and ${ }^{14} \mathrm{NH}_{2} \mathrm{Cl}$ to others. N-DBPs formation was observed from both nitrogenous and non-nitrogenous compounds (Table 1). In the case of nitrogenous compounds (aniline and amino acids), more than 50\% of DCAN and DCAcAm incorporated ${ }^{15} \mathrm{~N}$ originating from ${ }^{15} \mathrm{NH}_{2} \mathrm{Cl}$. Model compounds (i.e., resorcinol, phenol, aniline, and 3-hydroxybenzoic acid), including an aromatic ring activated by electron donating groups (i.e., $-\mathrm{OH}$ and $-\mathrm{NH}_{2}$ ) in their structure, were the most important precursors of DCAN and DCACAm. Despite their similar structures, tyrosine formed more DCAN and DCAcAm (i.e., $0.50 \%$ and $0.10 \%$ molar yield, respectively) than phenylalanine (i.e., $0.12 \%$ and $0.05 \%$, respectively). The activation of the aromatic ring by a hydroxyl group in the case of tyrosine favours chlorine electrophilic substitution leading to N-DBPs formation via ring-cleavage reaction (Hureiki et al., 1994). Phenol produced the highest 
proportion of DCAN (4.44\%) and resorcinol produced the highest proportion of DCAcAm $(0.83 \%)$.

163 Resorcinol is more reactive than phenol because of its additional hydroxyl group in meta position, resulting in chlorine substitutions in ortho and para positions of hydroxyl groups. Interestingly, TCM was the highest DBP produced from resorcinol, while DCAN was the dominant species from phenol (molar yield of TCM: $4.8 \%$ for resorcinol; $0.4 \%$ for phenol), suggesting different DBPs formation pathways from these two precursors. In this study, resorcinol was selected to explore N-DBPs formation mechanisms, since it produced DCAN and DCAcAm in relatively high concentrations.

Table 1. N-DBP yields from model aromatic compounds during chloramination ${ }^{\mathrm{a}}$

\begin{tabular}{|c|c|c|c|c|}
\hline & \multicolumn{2}{|c|}{ Molar yield $(\%)(\mathrm{SD})^{\mathrm{b}}$} & \multicolumn{2}{|c|}{${ }^{15} \mathrm{~N}-\mathrm{DBP}$ proportion $(\%)$} \\
\hline & DCAN & DCAcAm & ${ }^{15} \mathrm{~N}-\mathrm{DCAN}$ & ${ }^{15} \mathrm{~N}-\mathrm{DCAcAm}$ \\
\hline & \multicolumn{4}{|c|}{ Non-nitrogenous compounds } \\
\hline Resorcinol & $1.14(0.08)^{\mathrm{c}}$ & $0.83(0.04)^{\mathrm{c}}$ & NA & NA \\
\hline Phenol & $4.44(0.29)^{\mathrm{c}}$ & $0.22(0.01)^{\mathrm{c}}$ & NA & NA \\
\hline 3-Hydroxybenzoic acid & $1.00(0.07)$ & $0.22(0.01)$ & NA & NA \\
\hline Benzoic acid & $0.17(0.01)$ & $0.09(0.01)$ & NA & NA \\
\hline \multirow[t]{2}{*}{ 3-Phenylpropionic acid } & $0.10(0.01)$ & $0.04(0.01)$ & NA & NA \\
\hline & \multicolumn{4}{|c|}{ Nitrogenous compounds } \\
\hline Aniline & $1.73(0.11)$ & $0.12(0.01)$ & 85 & 74 \\
\hline Tyrosine & $0.50(0.03)^{\mathrm{c}}$ & $0.10(0.01)^{\mathrm{c}}$ & 83 & 70 \\
\hline Phenylalanine & $0.12(0.01)$ & $0.05(0.01)$ & 83 & 56 \\
\hline
\end{tabular}

Effect of monochloramine dose. Experiments were performed with resorcinol $(500 \mu \mathrm{M})$ for $72 \mathrm{~h}$ using different $\mathrm{NH}_{2} \mathrm{Cl}$ : resorcinol ratios (i.e., 1:1, 5:1 and 11.2:1) at $\mathrm{pH} 7$ (10 $\mathrm{mM}$ phosphate buffer). TCM was the dominant DBP identified for all ratios (i.e., 0.3\%, 11\% and 20\% yield), followed by DCAA (i.e., $0.1 \%, 3 \%$ and 7\%) (Figure S1). As hypothesized, the concentration of DBPs increased with increasing monochloramine dose since the application of higher oxidant doses facilitates the production of smaller and more halogenated by-products (Boyce and Hornig, 1983). The increase in DCAN and DCAcAm concentrations were proportionally higher than those in TCM and DCAA. The highest dose (i.e., 11.2:1 ratio) was selected in the following experiments since it maximized DBP formation.

Previous studies on chloramination of resorcinol and its chlorinated derivatives have been conducted in ether solution $(\sim 0.3 \mathrm{M})$ with $\mathrm{NH}_{2} \mathrm{Cl}$ :model compound ratio of 3:1 (Heasley et al., 1999). In these conditions, chloroketones were the major by-products identified (compound II and III in Scheme 1), and the formation of nitrogenous compounds was not reported, which could be due to the lower chloramine dose employed as compared to this study. 
Effect of reaction time. Kinetic experiments were performed with $500 \mu \mathrm{M}$ resorcinol at $\mathrm{pH} 7$ (10 mM phosphate buffer). Initial $\mathrm{NH}_{2} \mathrm{Cl}$ was $5.6 \mathrm{mM}\left(\mathrm{NH}_{2} \mathrm{Cl}\right.$ : resorcinol ratio of 11.2:1) and the total oxidant concentration remained in excess during all the reaction time (Figure S2). Figure 1 illustrates the kinetic profiles of DBPs formation. TCM was the major DBP found ( $20 \%$ yield after $72 \mathrm{~h}$ ), followed by DCAA (7.2\%). MCAA and DCAA were rapidly formed during the first $9 \mathrm{~h}$, suggesting that they might form directly from ring-cleavage. DCAN followed the same profile as TCM and reached $6.1 \%$ yield after $72 \mathrm{~h}$. DCAcAm and TCAcAm formation was slow within the first $4 \mathrm{~h}$ and then gradually increased, reaching $3.3 \%$ and $1.4 \%$ yield after $72 \mathrm{~h}$, respectively. Unlike DCAA and MCAA, TCAA increased slowly with time and its profile was very similar to that of TCAcAm. Low amounts of trichloroacetaldehyde (TCAcAl) $(0.14 \%$ at $72 \mathrm{~h})$, dichloroacetaldehyde (DCAcAl) $(0.08 \%)$ and TCAN $(0.02 \%)$ were detected.
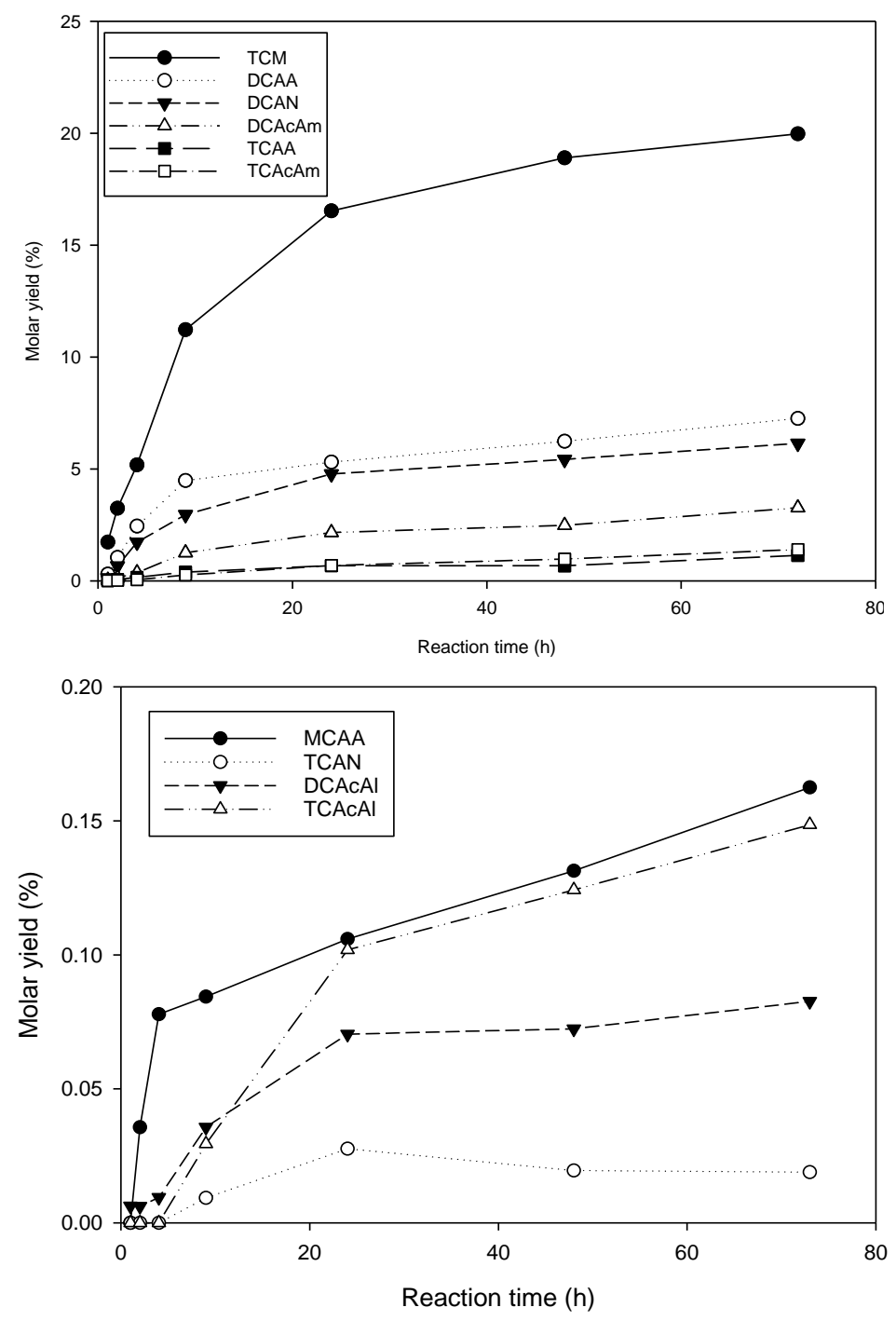

Figure 1. Kinetics of DBPs formation from chloramination of resorcinol. 
202 Effect of pH. Formation potential of DBPs from resorcinol upon $72 \mathrm{~h}$ of chloramination was 203 evaluated at different $\mathrm{pH}$ values (Figure 2). Dichlorinated DBPs (i.e., DCAA, DCAN and DCAcAm) 204 exhibited a maximum formation at $\mathrm{pH} \mathrm{8,} \mathrm{while} \mathrm{the} \mathrm{highest} \mathrm{formation} \mathrm{of} \mathrm{trichlorinated} \mathrm{DBPs} \mathrm{(i.e.,}$ 205 TCAA and TCAcAm) was found at $\mathrm{pH}$ 7. Taking into account the analytical error recorded at $\mathrm{pH} 5.5$ 206 (standard deviation: 3.5\% of molar yield), the TCM yields obtained at $\mathrm{pH} 5.5$ and $\mathrm{pH} 7$ should be 207 considered as relatively similar. Generally, the concentration of TCM increases with increasing $\mathrm{pH}$ 208 during chlorination of natural water due to base-catalyzed reaction (Hua and Reckhow, 2008). In 209 contrast to this, the TCM yields from chloramination of resorcinol gradually decreased as $\mathrm{pH}$ 210 increased from $\mathrm{pH}$ 7. Our result is consistent with previous observations, where the formation of TCM 211 from chloramination of resorcinol also decreased with increasing $\mathrm{pH}(\mathrm{pH}$ 6.5-12) under similar 212 experimental conditions (Cimetiere et al., 2010). It was proposed that the free chlorine released from $213 \mathrm{NH}_{2} \mathrm{Cl}$ hydrolysis plays a significant role on TCM formation during chloramination of resorcinol 214 (Cimetiere et al., 2010). In the organic-free solution of monochloramine, the concentration of free 215 chlorine is the lowest around pH 8.4 and increases with increasing pH (Cimetiere et al., 2010). 216 However, the free chlorine species shift from $\mathrm{HOCl}$ to $\mathrm{OCl}^{-}$as $\mathrm{pH}$ increases. TCM was also 217 demonstrated to form in significantly lower amounts during chlorination of resorcinol in alkaline 218 conditions $\left(\mathrm{pH}>10\right.$ ) (Boyce et al., 1983), most likely due to the less reactivity of $\mathrm{OCl}^{-}$with 219 intermediate precursors of chloroform. Therefore, the pH-dependency of TCM yield might be related 220 to the free chlorine from the hydrolysis of monochloramine, as well as the distribution of free chlorine 221 species with $\mathrm{pH}$. Most DBPs exhibited a substantially lower formation at $\mathrm{pH} 10$, suggesting that an 222 alternative degradation pathway of resorcinol may exist. Reduction of N-DBPs from $\mathrm{pH} 8$ to $\mathrm{pH} 10$ 223 was possibly related to their base catalysed hydrolysis as well (Reckhow et al., 2001; Yu et al., 2015). 224 No resorcinol or chlorinated analogues were detected in samples at $\mathrm{pH} \mathrm{7,8}$ and 10, indicating that 225 they completely decomposed to intermediates or final by-products after $72 \mathrm{~h}$, but large peaks of 226 mono-, di- and tri-chlororesorcinol were still detected from GC-MS full scan after $72 \mathrm{~h}$ at $\mathrm{pH} 4$ 227 (Figure S3). This might explain the low non-aromatic DBP formation at $\mathrm{pH} 4$, as the reaction did not 228 lead to significant ring-opening of resorcinol. 

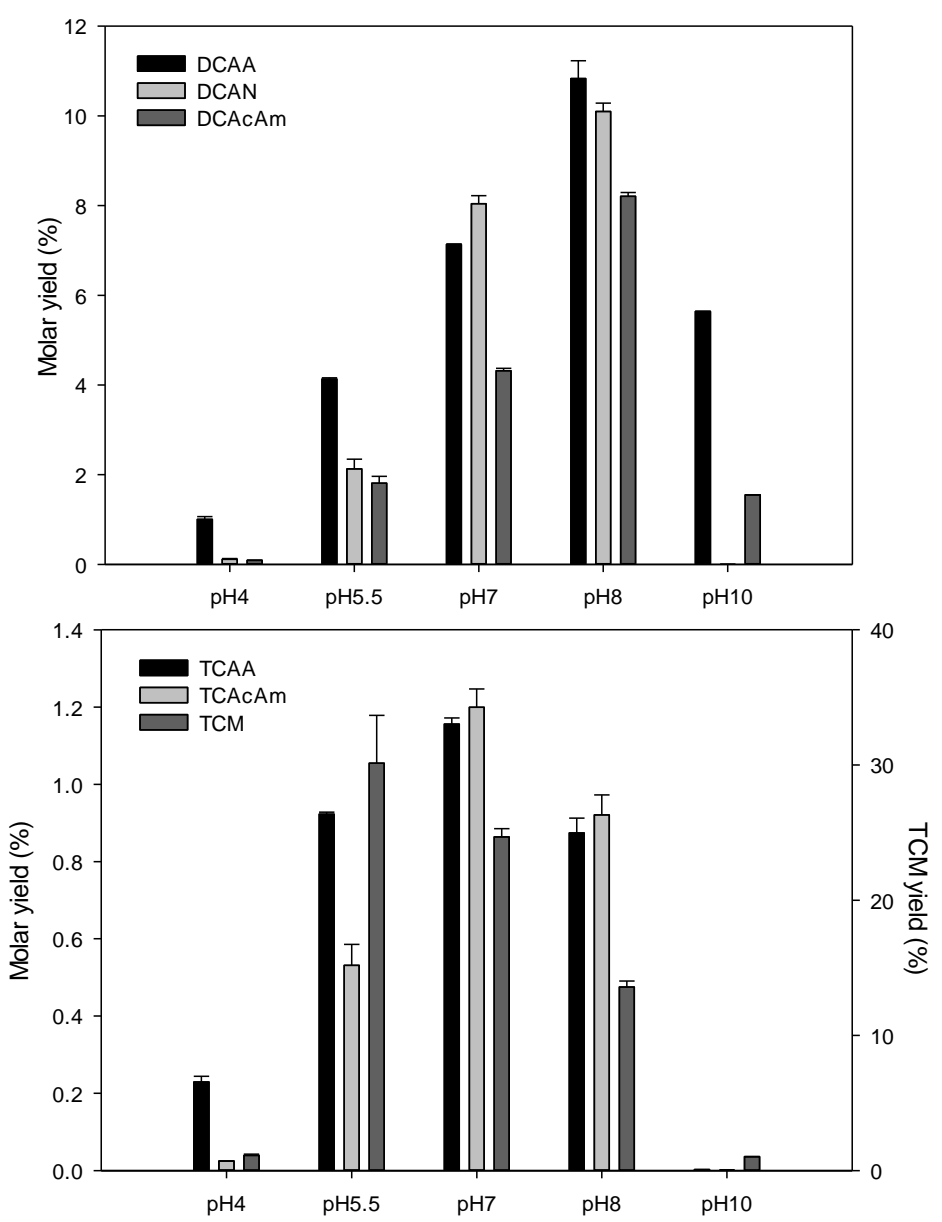

Figure 2. Effect of $\mathrm{pH}$ on DBPs formation from chloramination of resorcinol.

Identification of nitrogenous heterocyclic compounds. Resorcinol $(500 \mu \mathrm{M})$ was chloraminated $\left(5.6 \mathrm{mM} \mathrm{NH}_{2} \mathrm{Cl}\right)$ at $\mathrm{pH} 7$ to investigate its decomposition mechanism and to identify the intermediate products that could lead to the formation of N-DBPs (e.g., DCAcAm). Several peaks were observed in the PCI chromatogram recorded on the GC-QTOF such as DCAN (retention time $(\mathrm{RT})=3.7 \mathrm{~min}$ ), DCAcAm $(\mathrm{RT}=7.5 \mathrm{~min})$, TCAcAm $(\mathrm{RT}=8.6 \mathrm{~min})$, and other unknown compounds $(\mathrm{P} 131$ at $\mathrm{RT}=$ $8.5 \mathrm{~min}, \mathrm{P} 197$ at RT= $10.6 \mathrm{~min}, \mathrm{P} 215$ at $\mathrm{RT}=11.0 \mathrm{~min}$ and $\mathrm{P} 249$ at $\mathrm{RT}=11.5 \mathrm{~min}$ ) (Figure S4). P215 and P249 were two major compounds exhibiting larger peak areas than known DBPs (i.e., DCAN, DCAcAm and TCAcAm). Molecular formulas and structures of these compounds were proposed based on their accurate mass obtained from GC-QTOF and fragmentation patterns observed in EI and PCI modes (Table 2). 
Table 2. Chloramination by-products of resorcinol detected by GC-QTOF

\begin{tabular}{|c|c|c|c|c|c|}
\hline Compound & $\begin{array}{l}\text { Exact } \\
\text { Mass }\end{array}$ & $\begin{array}{c}\text { Accurate } \\
\text { Mass }\end{array}$ & $\begin{array}{l}\text { Error } \\
(\mathrm{ppm})\end{array}$ & $\begin{array}{l}\text { Molecular } \\
\text { Formula }\end{array}$ & Proposed Structures \\
\hline P215 & $\begin{array}{c}215.9380 \\
{[\mathrm{M}+\mathrm{H}]^{+}}\end{array}$ & $\begin{array}{c}215.9379 \\
{[\mathrm{M}+\mathrm{H}]^{+}}\end{array}$ & 0.64 & $\mathrm{C}_{5} \mathrm{H}_{4} \mathrm{NO}_{2} \mathrm{Cl}_{3}$ & \\
\hline P249 & $\begin{array}{c}249.8990 \\
{[\mathrm{M}+\mathrm{H}]^{+}}\end{array}$ & $\begin{array}{c}249.8988 \\
{[\mathrm{M}+\mathrm{H}]^{+}}\end{array}$ & 1.06 & $\mathrm{C}_{5} \mathrm{H}_{3} \mathrm{NO}_{2} \mathrm{Cl}_{4}$ & \\
\hline P131 & $\begin{array}{c}131.9845 \\
{[\mathrm{M}+\mathrm{H}]^{+}}\end{array}$ & $\begin{array}{c}131.9847 \\
{[\mathrm{M}+\mathrm{H}]^{+}}\end{array}$ & -0.13 & $\mathrm{C}_{4} \mathrm{H}_{2} \mathrm{NO}_{2} \mathrm{Cl}$ & \\
\hline $\mathrm{P} 197^{\mathrm{a}}$ & $\begin{array}{c}197.9270 \\
{[\mathrm{M}+\mathrm{H}]^{+}}\end{array}$ & $\begin{array}{c}197.9262 \\
{[\mathrm{M}+\mathrm{H}]^{+}}\end{array}$ & 6.43 & $\mathrm{C}_{5} \mathrm{H}_{2} \mathrm{NOCl}_{3}$ & \\
\hline $\mathrm{P} 179^{\mathrm{b}}$ & 178.9540 & N.D & N.D & $\mathrm{C}_{5} \mathrm{H}_{3} \mathrm{NO}_{2} \mathrm{Cl}_{2}$ & \\
\hline $\mathrm{P} 198^{\mathrm{c}}$ & 197.9042 & 197.9252 & -106.05 & $\mathrm{C}_{5} \mathrm{HO}_{2} \mathrm{Cl}_{3}$ & \\
\hline
\end{tabular}

${ }^{\mathrm{a}}$ Confirmed by NIST database ( $94 \%$ similarity)

bDetected by GC-MSD; also reported in a previous study (Haddon et al., 1996); N.D: not detected by GC-QTOF.

${ }^{c}$ Confirmed by NIST database (95\% similarity); also reported in previous studies (Norwood et al., 1980; Boyce and Hornig, 1983).

The EI mass spectrum of P215 exhibited two dominant ion clusters (m/z 132/134 and 114/116) comprising one chlorine atom, with a difference of $18 \mathrm{Da}$ corresponding to the loss of one water molecule (i.e., dehydroxylation) (Figure S5a). The corresponding PCI mas spectrum contained a major ion cluster $\mathrm{m} / \mathrm{z}$ 216/218/220/222 (i.e., $[\mathrm{M}+\mathrm{H}]^{+}$) with relative abundance, suggesting that this compound had three chlorine atoms (Figure S5b). The odd-numbered nominal mass (i.e., $215 \mathrm{Da}$ ) indicated an odd-number of nitrogen atoms. Loss of 83 along with two chlorine was observed from $\mathrm{m} / \mathrm{z} 215$ to $\mathrm{m} / \mathrm{z} 132$, indicating the loss of a $\left(-\mathrm{CHCl}_{2}\right)$ group. The PCI mass spectrum obtained from GC-QTOF showed an accurate mass of 215.9379 for $[\mathrm{M}+\mathrm{H}]^{+}$. Accordingly, $\mathrm{C}_{5} \mathrm{H}_{4} \mathrm{NO}_{2} \mathrm{Cl}_{3}$ was confirmed to be the molecular formula of this compound $(0.64 \mathrm{ppm})$. Based on the fragmentation pattern and accurate mass of fragments obtained from EI and PCI modes (Table S2), the proposed molecular structure of this compound is 3-chloro-5-hydroxy-1H-pyrrole-2-one with dichloromethyl group. It is structurally very similar to MX (3-chloro-4-(dichloromethyl)-5-hydroxy-2(5H)-furanone), the strong mutagen found from chlorinated drinking water and humic water (Hemming et al., 1986; 
Kronberg et al., 1988). Additionally, the corresponding methyl ester form of P215 was also detected after derivatization of the MTBE extract using acidic methanol, with a molecular formula of $\mathrm{C}_{6} \mathrm{H}_{6} \mathrm{NO}_{2} \mathrm{Cl}_{3}$ (9.52ppm). The corresponding EI and PCI mass spectra presented a loss of $31 \mathrm{Da}(-$ $\mathrm{OCH}_{3}$ group) from m/z 229 to m/z 198 (Text S2).

267

268

269

270

271

272

273

274

275

276

277

278

279

280

281

282

283

284

285

286

287

288

289

290

291

292

293

294

295

296

297

298

A similar method was used for the identification of other compounds. P249 exhibited a similar EI mass spectrum to P215, with dominant ion clusters $\mathrm{m} / \mathrm{z} 132 / 134$ and 114/116. However, its PCI mass spectrum showed a main molecular ion (i.e., $[\mathrm{M}+\mathrm{H}]^{+}$) at $\mathrm{m} / \mathrm{z} 250$ including four chlorine atoms. Therefore, we proposed P249 as an analogue of P215 with an additional chlorine atom or as 6hydroxy-2-pyridone with four chlorine atoms (Text S3).

The EI mass spectrum of P131 contained ion clusters m/z 131/133, 103/105 and 88/90, which was similar to the mass spectrum of 3-chloro-2,5-furandione present in the NIST database (Figure S6). However the molecular ion m/z 132 (i.e., a nominal mass of $131 \mathrm{Da}$ ) obtained from PCI mass spectrum suggested the presence of a nitrogen atom. The accurate mass of ion $\mathrm{m} / \mathrm{z} 131.9847$ (i.e., $[\mathrm{M}+\mathrm{H}]^{+}$adduct) supported a molecular formula of $\mathrm{C}_{4} \mathrm{H}_{2} \mathrm{NO}_{2} \mathrm{Cl}(-0.13 \mathrm{ppm})$. Accordingly, $\mathrm{P} 131$ was tentatively identified as 3-chloro-2,5-pyrroledione (chloromaleimide) (Text S4).

Product P197 was confirmed as 2-hydroxy-3,5,6-trichloropyridine because a library match of its spectrum was obtained from NIST database (94\% similarity) and the corresponding formula $\left(\mathrm{C}_{5} \mathrm{H}_{2} \mathrm{NOCl}_{3}\right)$ was derived from its accurate mass (Figure $\mathrm{S} 7$ ).

Product P179 was proposed as another pyridine-based compound (i.e., dichloro-pyridine-dione) or its isomer, chloro-pyrrole-dione with dichloromethylene group. The formation of the latter was reported during chlorination of poultry chiller water (Haddon et al., 1996). P179 was only detected from GCMSD (DB-1701 column) (Figure S8), but was not found by high resolution analysis on GC-QTOF. 2,2,4-trichloro-1,3-cyclopentenedione (P198) and its isomer were detected (95\% similarity with NIST database) from the MTBE extract after derivatization using acidic methanol (RT=9.7min) (Figure S9). The formation of 2,2,4-trichloro-1,3-cyclopentenedione has been reported as a chlorination byproduct of resorcinol (Boyce et al., 1983; Norwood et al., 1980).

Because of the lack of analytical standards, the proposed structures of P215, P249, P131 and P179 could not be confirmed. However, the formation of halogenated heterocyclic compounds (e.g., halogenated furanones and pyrroles), which are structurally similar to the compounds found from this study, has been reported in several chlorination studies (Table S3). The most known halogenated furanone formed by chlorination of drinking water is the highly mutagenic MX and its analogues (Hemming et al., 1986; Kronberg and Vartiaine, 1988; Meier et al., 1986). In a previous study on chlorination of phenolic compounds, resorcinol was found to produce MX, but in low concentration at acidic pH (i.e., $0.01 \mathrm{mmol} / \mathrm{mol}, \mathrm{pH}$ 2) (Långvik et al., 1991). Several compounds similar to MX were identified from chlorination of orcinol (Tretyakova et al., 1994). Moreover, it was found that MX can be produced during chloramination of humic water (Backlund et al., 1988) and fulvic acid solution 
(Kanniganti et al., 1992). Dichloromaleic anhydride (3,4-dichloro-2,5-furandione) and 300 monochloromaleic anhydride (3-chloro -2,5-furandione), which are structurally similar to the 301 chlorinated pyrroledione found from this study (i.e., P131), are major chlorination by-products of

302

303

304

305

306

307

308

309

310

311

312

313

314

315

316

317

318

319

320

321

322

323

324

325 resorcinol (Rook, 1980) or swimming pool waters (Richardson et al., 2010). Similarly, 3-bromo-2,5furandione was reported from bromination of resorcinol (Boyce et al., 1983). Dichlorinated analogue of P131, 3,4-dichloro-2,5-pyrroledione, was detected with three other chlorinated cyclic imides in chlorinated poultry chiller water (Haddon et al., 1996). These five-carbon chlorinated cyclic imides were structurally similar to P215 and found to be direct acting Ames mutagens (Freeman et al., 2001; Haddon et al., 1996). Moreover, the presence of brominated pyrroles was reported from chlorinated saline wastewater effluents (M. Yang et al., 2014). Tribromopyrrole is a major chlorination byproduct of bromide-containing waters and has been demonstrated to be strongly cytotoxic and genotoxic to mammalian cells (Richardson et al., 2003).

Based on the potential toxicity of halogenated furanone, cyclic imide and pyrrole compounds (Freeman et al., 2001; Haddon et al., 1996; Hemming et al., 1986; Kronberg et al., 1988; Richardson et al., 2003), the halogenated nitrogenous heterocyclic compounds identified from this study could be also strong mutagenic products and would require toxicity assays.

6

7

8

9



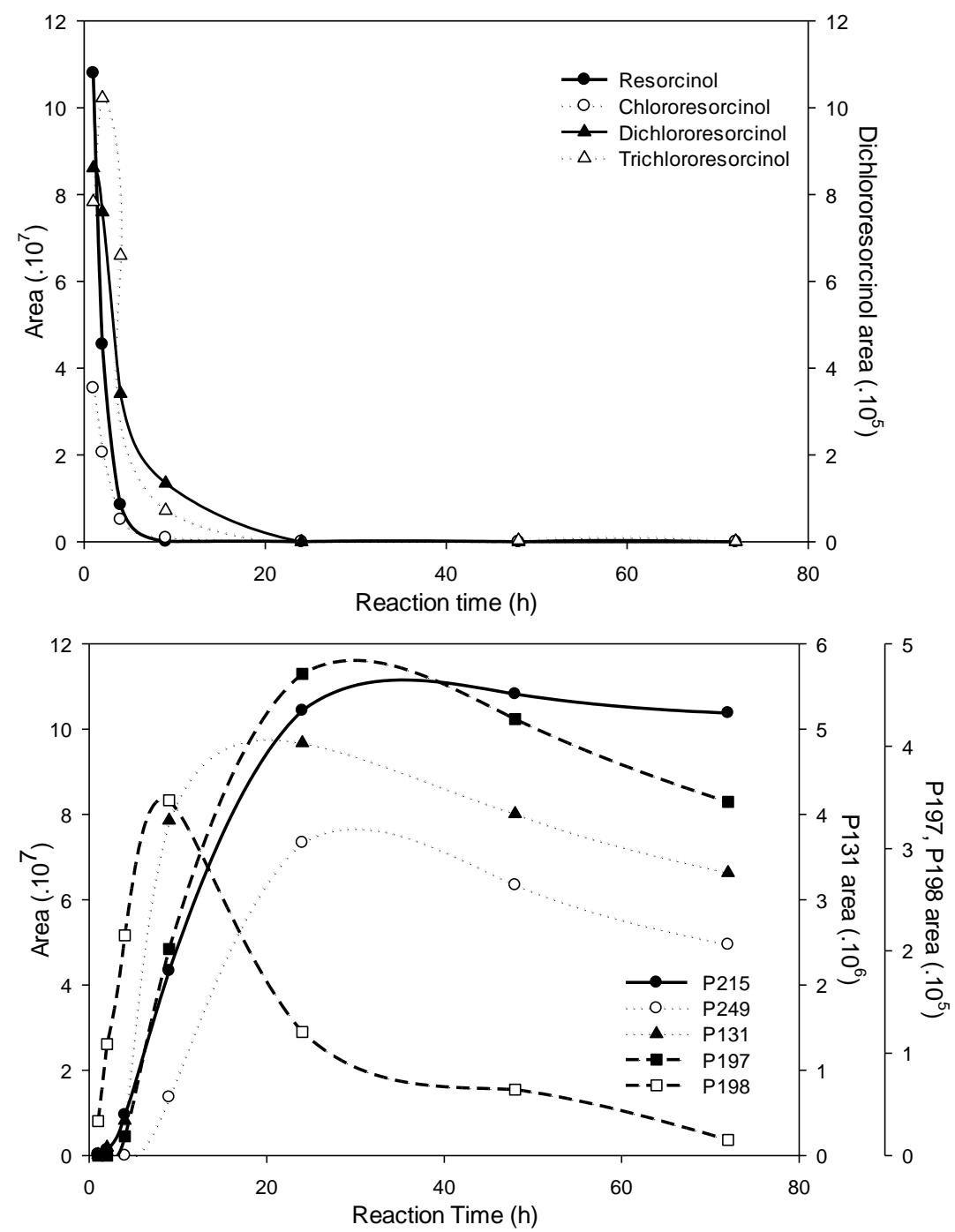

Figure 3. (a) Degradation of resorcinol and its chlorinated derivatives and (b) formation of by-products during chloramination $(5.6 \mathrm{mM})$ of resorcinol $(500 \mu \mathrm{M})$ at $\mathrm{pH}=7.0(10$ $\mathrm{mM}$ phosphate buffer)

Effect of reaction time and pH on heterocyclic compounds formation. Figure 3 shows the evolution of peak areas of chlorinated derivatives of resorcinol and identified by-products with reaction time. Mono-, di-and tri-chlorinated derivatives of resorcinol were detected after $1 \mathrm{~h}$ of reaction time, indicating a fast electrophilic substitution of the aromatic ring by chlorine. The majority of resorcinol and its chlorinated derivatives (>90\%) decomposed within the first $9 \mathrm{~h}$ of reaction (Figure 3a). It has been proposed that chlorination and chloramination of aqueous solutions of resorcinol lead to the formation of a pentachlororesorcinol intermediate (compound I in Scheme 1), which then undergoes hydrolysis and decarboxylation to produce chloroform and other chlorinated compounds (Boyce et al., 1983; De Leer et al., 1985; Heasley et al., 1999; Rook, 1980). The nitrogenous heterocyclic compounds found in this study exhibited the largest peak areas on GC-MS chromatograms, suggesting that inorganic nitrogen incorporation is a major reaction pathway during chloramination of resorcinol. A chloramination mechanism of resorcinol is proposed on Scheme 1, where the carbonyl group of the pentachlororesorcinol intermediate is attacked by electron pairs of 
nitrogen atom from $\mathrm{NH}_{2} \mathrm{Cl}$ or oxygen atom from $\mathrm{H}_{2} \mathrm{O}$. The ring-cleavage by-product from nitrogen attack then undergoes intramolecular nucleophilic substitution to form a nitrogenous heterocyclic compound and finally P249 (Scheme 1a). A similar ring contraction mechanism is proposed for the formation of 2,2,4-trichloro-1,3-cyclopentenedione (i.e., P198), based on its formation pathway previously proposed during chlorination of resorcinol (Rook, 1980; Tretyakova et al., 1994) (Scheme 1b). P198 was formed rapidly from $1 \mathrm{~h}$ to $9 \mathrm{~h}$ and gradually degraded (Figure 3b). We propose that in excess of $\mathrm{NH}_{2} \mathrm{Cl}, \mathrm{P} 198$ will be an intermediate product of nitrogenous heterocyclic compounds (i.e., P131, P215 and P249) through nitrogen attack and intramolecular nucleophilic substitution. As shown in Figure 3b, P131 and P249 started to degrade after $24 \mathrm{~h}$ of reaction time. These compounds comprise a Cl-C-CO-NH- moiety, which could be responsible for HAcAms and haloacetaldehydes (HAcAls) formation with an excess of oxidant (Scheme 1).

Figure S10 presents the peak area of P131, P197, P198 and P215 after $72 \mathrm{~h}$ of reaction time at different pHs. The highest formation was found in neutral ( $\mathrm{pH} 7$ for P197 and P215) or weak acidic (pH 5.5 for P131 and P198) condition. Low formation of these compounds at $\mathrm{pH} 4$ is in accordance with the higher formation of chlorinated derivatives of resorcinol (Figure S3), supporting the hypothesis that the reaction at $\mathrm{pH} 4$ did not lead to significant ring-opening of resorcinol. Little or no nitrogenous heterocyclic compounds were detected in alkaline conditions ( $\mathrm{pH} 8.5$ and 10), suggesting that they might decompose at higher $\mathrm{pH}$ to form other by-products. To support our hypothesis, MX mainly undergoes hydrolytic degradation at pH higher than 8 (Kronberg et al., 1989). 
Scheme 1. Proposed formation pathway of by-products from chloramination of resorcinol (I: pentachlororesorcinol; II, III: compounds identified in a previous study (Heasley et al., 1999). b: adapted from previous studies (Rook, 1980; Heasley et al., 1999; Tretyakova et al., 1994). P215, P2491,2: possible structures for P215, P249).

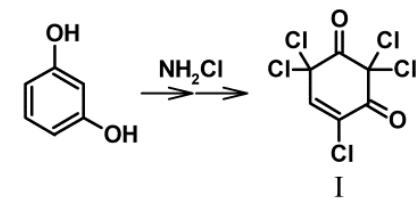

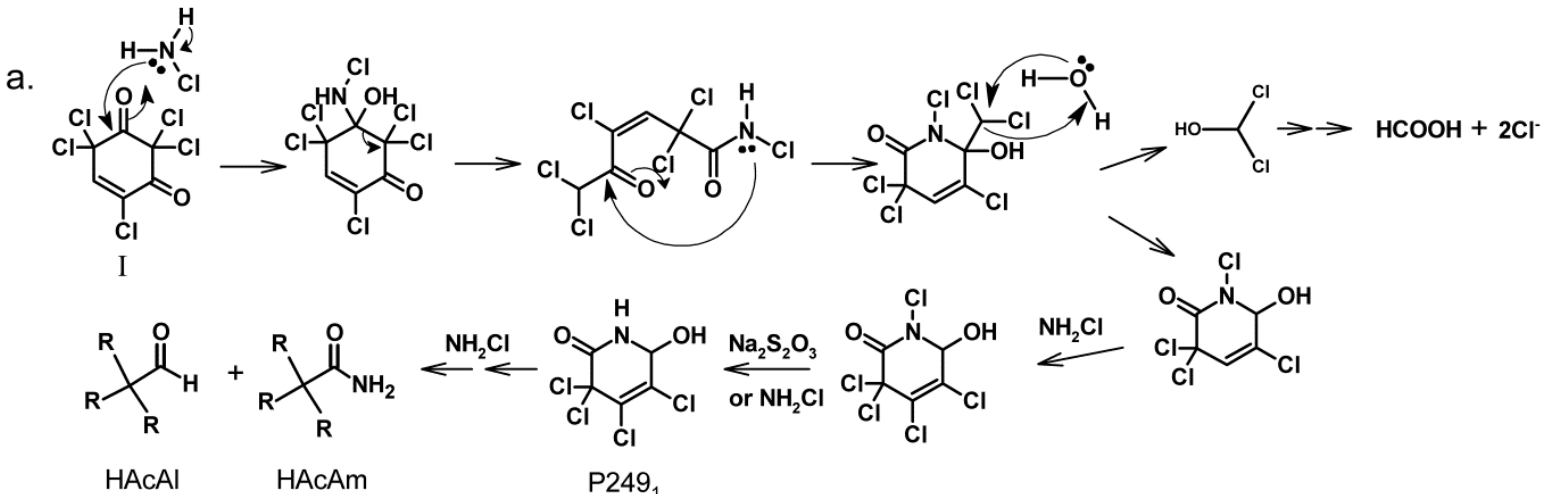

b.

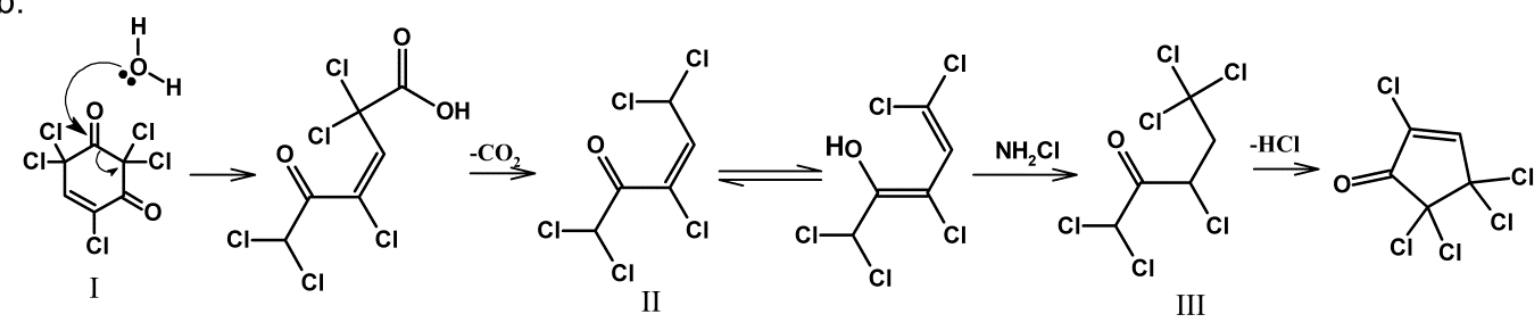<smiles>CC1=CC(O)(C(Cl)Cl)N(Cl)C1=O</smiles>

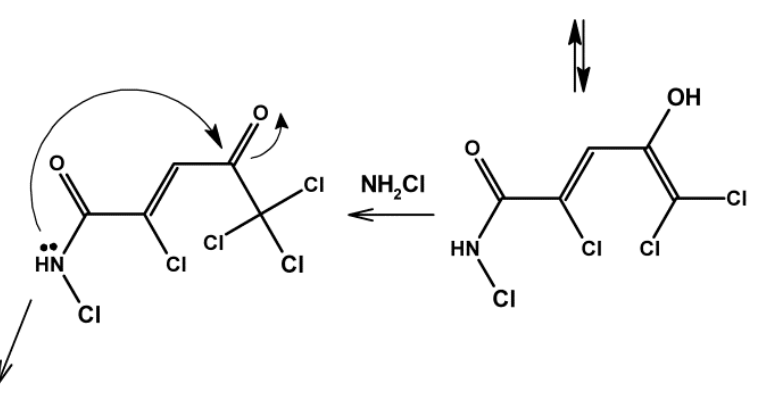

$\mathrm{Na}_{2} \mathrm{~S}_{2} \mathrm{O}_{3}$ or $\mathrm{NH}_{2} \mathrm{Cl}$

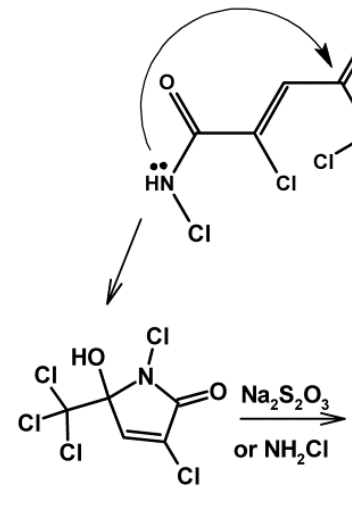<smiles>O=C1NC(O)(C(Cl)(Cl)Cl)C=C1Cl</smiles>

$\mathrm{P} 249_{2}$<smiles>O=C1C=C(Cl)C(=O)C1NC1CCCC1</smiles>

P131<smiles>[Y5]C(=O)C([R])([R])[R]</smiles>

HAcAm

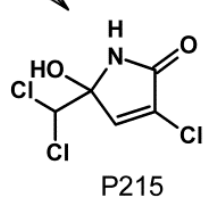

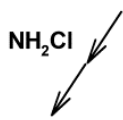


382 High concentrations of model compounds and high monochloramine doses were used in this study to maximize the formation of by-products and thus facilitate their detection and identification by GC-MS in full scan mode. The possible reasons why the products identified in this study (i.e., chlorinated nitrogenous heterocyclic compounds) have not yet been observed during the chloramination of real water samples, include: (1) many studies about the identification of unknown DBPs were mainly focused on chlorination process, and less on chloramination; (2) the amounts of by-products formed in real case disinfection scenarios (i.e., low precursors concentration and low monochloramine doses) were not sufficient to be detected during analytical screenings. From another study we detected a compound likely to be dibromo-pyrrole-dione (molecular ion $\mathrm{m} / \mathrm{z} 253$ ), similar base structure to P131, during chloramination $\left(14.9 \mathrm{mg} / \mathrm{L} \mathrm{Cl}_{2}\right.$ ) of a treated wastewater effluent (5 mg/L DOC) containing 2.5 $\mathrm{mg} / \mathrm{L}$ of bromide ion. It exhibited a similar mass spectrum to dibromo-furan-dione ( $\mathrm{m} / \mathrm{z} 254)$. The accurate mass obtained from GC-QTOF (m/z 252.8408) supports the molecular formula of $\mathrm{C}_{4} \mathrm{HNO}_{2} \mathrm{Br}_{2}(11 \mathrm{ppm})$ (Figure S11). The occurrence of brominated pyrroledione indicated that this class of compounds can be formed during real chloramination scenarios. Similar screening of chlorinated or brominated pyrroledione compounds should be performed during chloramination of natural waters or NOM in order to confirm their formation from other organic matrices.

Aromatic compounds that do not contain nitrogen can react with monochloramine to produce N-DBPs through inorganic nitrogen incorporation. The potential formation of nitrogenous heterocyclic compounds is of importance for water treatment facilities using chloramine as disinfectant since they could be substantially toxic due to their similarity to known mutagenic compounds (e.g., MX). The removal of aromatic NOM must be optimized to avoid the production of these potentially toxic N-DBPs.

404

\section{SUPPORTING INFORMATION}

406 Detailed information on analytical methods, total ion chromatogram from GC-MS and mass spectrum 407 of each compound in EI and PCI mode are available in supporting information.

\section{SUPPORTING INFORMATION}

409 We acknowledge the financial support from Water Research Australia and Water Corporation of Western Australia (WaterRA Postgraduate Scholarship). 
Backlund, P., Kronberg, L., \& Tikkanen, L. (1988). Formation of AMES mutagenicity and of the strong bacterial mutagen 3-chloro-4-(dichloromethyl)-5-hydroxy-2(5H)-furanone and other halogenated compounds during disinfection of humic water. Chemosphere, 17(7), 1329-1336.

Bond, T., Huang, J., Templeton, M. R., \& Graham, N. (2011). Occurrence and control of nitrogenous disinfection by-products in drinking water - A review. Water Research, 45(15), 4341-4354.

Boyce, S. D., \& Hornig, J. F. (1983). Reaction pathways of trihalomethane formation from the halogenation of dihydroxyaromatic model compounds for humic acid. Environmental Science \& Technology, 17(4), 202-211.

Chu, W. H.; Gao, N. Y. (2009) Determination of nitrogenous disinfection byproducts chloroacetamides in drinking water by gas chromatography-mass spectrometry. Chin. J. Anal. Chem., 37(1), 103-106.

Chu, W.; Krasner, S. W.; Gao, N.; Templeton, M. R.; Yin, D. (2016) Contribution of the Antibiotic Chloramphenicol and Its Analogues as Precursors of Dichloroacetamide and Other Disinfection Byproducts in Drinking Water. Environ. Sci. Technol., 50(1), 388-396.

Chu, W., Li, X., Bond, T., Gao, N., \& Yin, D. (2016). The formation of haloacetamides and other disinfection by-products from non-nitrogenous low-molecular weight organic acids during chloramination. Chemical Engineering Journal, 285, 164-171.

Chuang, Y. H., McCurry, D. L., Tung, H. H., \& Mitch, W. A. (2015). Formation Pathways and TradeOffs between Haloacetamides and Haloacetaldehydes during Combined Chlorination and Chloramination of Lignin Phenols and Natural Waters. Environmental Science and Technology, 49(24), 14432-14440.

Cimetiere, N., Dossier-Berne, F., \& De Laat, J. (2010). Effect of some parameters on the formation of chloroform during chloramination of aqueous solutions of resorcinol. Water Research, 44(15), 4497-4504.

De Leer, E. W. B., \& Erkelens, C. (1985). Chloroform production from model compounds of aquatic humic material the role of pentachlororesorcinol as an intermediate. Science of the Total Environment, The, 47(C), 211-216.

Dotson, A., Westerhoff, P., \& Krasner, S. W. (2009). Nitrogen enriched dissolved organic matter (DOM) isolates and their affinity to form emerging disinfection by-products. Water Science and Technology, 60(1), 135-143.

Freeman, B. A., Wilson, R. E., Binder, R. G., \& Haddon, W. F. (2001). Halogenated 2,5pyrrolidinediones: Synthesis, bacterial mutagenicity in Ames tester strain TA-100 and semiempirical molecular orbital calculations. Mutation Research - Genetic Toxicology and Environmental Mutagenesis, 490(2), 89-98.

Haddon, W. F., Binder, R. G., Wong, R. Y., Harden, L. A., Wilson, R. E., Benson, M., \& Stevens, K. L. (1996). Potent Bacterial Mutagens Produced by Chlorination of Simulated Poultry Chiller Water. Journal of Agricultural and Food Chemistry, 44(1), 256-263.

Heasley, V. L., Alexander, M. B., Deboard, R. H., Hanley Jr, J. C., McKee, T. C., Wadley, B. D., \& Shellhamer, D. F. (1999). Reactions of resorcinol and its chlorinated derivatives with monochloramine: Identification of intermediates and products. Environmental Toxicology and Chemistry, 18(11), 2406-2409.

Hemming, J., Holmbom, B., Reunanen, M., \& Kronberg, L. (1986). Determination of the strong mutagen 3-chloro-4-(dichloromethyl)-5-hydroxy-2 $(5 \mathrm{H})$-furanone in chlorinated drinking and humic waters. Chemosphere, 15(5), 549-556.

Hua, G., Kim, J., \& Reckhow, D. A. (2014). Disinfection byproduct formation from lignin precursors. Water Research, 63, 285-295.

Hua, G., \& Reckhow, D. A. (2007). Comparison of disinfection byproduct formation from chlorine and alternative disinfectants. Water Research, 41(8), 1667-1678.

Hua, G.; Reckhow, D. A. (2008) DBP formation during chlorination and chloramination: Effect of reaction time. $\mathrm{pH}$, dosage, and temperature. J. Am. Water Works Assoc., 100 (8), 82-95+12

Hureiki, L.; Croué, J. P.; Legube, B. (1994) Chlorination studies of free and combined amino acids. Water Res., 28(12), 2521-2531. 
Huang, H., Wu, Q. Y., Hu, H. Y., \& Mitch, W. A. (2012). Dichloroacetonitrile and dichloroacetamide can form independently during chlorination and chloramination of drinking waters, model organic matters, and wastewater effluents. Environmental Science and Technology, 46(19), 10624-10631.

Kanniganti, R., Johnson, J. D., Ball, L. M., \& Charles, M. J. (1992). Identification of compounds in mutagenic extracts of aqueous monochloraminated fulvic acid. Environmental Science and Technology, 26(10), 1998-2004.

Kimura, S. Y., Komaki, Y., Plewa, M. J., \& Mariñas, B. J. (2013). Chloroacetonitrile and N,2dichloroacetamide formation from the reaction of chloroacetaldehyde and monochloramine in water. Environmental Science and Technology, 47(21), 12382-12390.

Krasner Stuart, W., McGuire Michael, J., Jacangelo Joseph, G., Patania Nancy, L., Reagan Kevin, M., \& Marco Aieta, E. (1989). Occurrence of disinfection by-products in US drinking water. Journal / American Water Works Association, 81(8), 41-53.

Krasner, S. W., Weinberg, H. S., Richardson, S. D., Pastor, S. J., Chinn, R., Sclimenti, M. J., Onstad, G. D., \& Thruston Jr, A. D. (2006). Occurrence of a new generation of disinfection byproducts. Environmental Science and Technology, 40(23), 7175-7185.

Kronberg, L., \& Christman, R. F. (1989). Chemistry of mutagenic by-products of water chlorination. Science of the Total Environment, The, 81-82(C), 219-230.

Kronberg, L., \& Vartiaine, T. (1988). Ames mutagenicity and concentration of the strong mutagen 3chloro-4-(dichloromethyl)-5-hydroxy-2 $(5 \mathrm{H})$-furanone and of its geometric isomer E-2-chloro3-(dichloromethyl)-4-oxo-butenoic acid in chlorine-treated tap waters. Mutation Research/Genetic Toxicology, 206(2), 177-182.

Långvik, V.-A., Hormi, O., Tikkanen, L., \& Holmbom, B. (1991). Formation of the mutagen 3chloro-4-(dichloromethyl)-5-hydroxy-2 $(5 \mathrm{H})$-furanone and related compounds by chlorination of phenolic compounds. Chemosphere, 22(5), 547-555.

Le Roux, J., Nihemaiti, M., \& Croué, J.-P. (2016). The role of aromatic precursors in the formation of haloacetamides by chloramination of dissolved organic matter. Water Research, 88, 371-379.

Meier, J. R.; Ringhand, H. P.; Coleman, W. E. (1986) Mutagenic by-products from chlorination of humic acid. Environ. Health Perspect., Vol. 69, 101-107.

Muellner, M. G., Wagner, E. D., McCalla, K., Richardson, S. D., Woo, Y. T., \& Plewa, M. J. (2007). Haloacetonitriles vs. regulated haloacetic acids: Are nitrogen-containing DBFs more toxic? Environmental Science and Technology, 41(2), 645-651.

Norwood, D. L., Johnson, J. D., Christman, R. F., Mass, J. R., \& Bobenrieth, M. J. (1980). Reactions of chlorine with selected aromatic models of aquatic humic material. Environmental Science and Technology, 14(2), 187-190.

Oliver, B. G. (1983). Dihaloacetonitriles in drinking water: Algae and fulvic acid as precursors. Environmental Science and Technology, 17(2), 80-83.

Pedersen, I. E. J., Urbansky, E. T., Mariñas, B. J., \& Margerum, D. W. (1999). Formation of cyanogen chloride from the reaction of monochloramine with formaldehyde. Environmental Science and Technology, 33(23), 4239-4249.

Plewa, M. J., Wagner, E. D., Jazwierska, P., Richardson, S. D., Chen, P. H., \& McKague, A. B. (2004). Halonitromethane Drinking Water Disinfection Byproducts: Chemical Characterization and Mammalian Cell Cytotoxicity and Genotoxicity. Environmental Science and Technology, 38(1), 62-68.

Reckhow, D. A., MacNeill, A. L., Platt, T. L., MacNeill, A. L., \& McClellan, J. N. (2001). Formation and degradation of dichloroacetonitrile in drinking waters. Journal of Water Supply: Research and Technology - AQUA, 50(1), 1-13.

Richardson, S. D., DeMarini, D. M., Kogevinas, M., Fernandez, P., Marco, E., Lourencetti, C., Ballesté, C., Heederik, D., Meliefste, K., McKague, A. B., Marcos, R., Font-Ribera, L., Grimalt, J. O., \& Villanueva, C. M. (2010). What's in the pool? a comprehensive identification of disinfection by-products and assessment of mutagenicity of chlorinated and brominated swimming pool water. Environmental Health Perspectives, 118(11), 1523-1530.

Richardson, S. D., Thruston Jr, A. D., Rav-Acha, C., Groisman, L., Popilevsky, I., Juraev, O., Glezer, V., McKague, A. B., Plewa, M. J., \& Wagner, E. D. (2003). Tribromopyrrole, brominated 
acids, and other disinfection byproducts produced by disinfection of drinking water rich in bromide. Environmental Science and Technology, 37(17), 3782-3793.

Rook, J. J. (1977). Chlorination reactions of fulvic acids in natural waters. Environmental Science and Technology, 11(5), 478-482.

Rook, J. J. (1980). Possible pathways for the formation of chlorinated degradation products during chlorination of humic acids and resorcinol. Water Chlorination: Environmental Impact and Health Effects, 3, 85-98.

Schreiber, I. M., \& Mitch, W. A. (2005). Influence of the order of reagent addition on NDMA formation during chloramination. Environmental Science and Technology, 39(10), 38113818.

Seidel, C. J., McGuire, M. J., Summers, R. S., \& Via, S. (2005). Have utiities switched to chloramines? Journal / American Water Works Association, 97(10), 87-97.

Tretyakova, N. Y., Lebedev, A. T., \& Petrosyan, V. S. (1994). Degradative pathways for aqueous chlorination of orcinol. Environmental Science and Technology, 28(4), 606-613.

Westerhoff, P., \& Mash, H. (2002). Dissolved organic nitrogen in drinking water supplies: A review. Journal of Water Supply: Research and Technology - AQUA, 51(8), 415-448.

Yang, M., \& Zhang, X. (2014). Halopyrroles: A new group of highly toxic disinfection byproducts formed in chlorinated saline wastewater. Environmental Science and Technology, 48(20), 11846-11852.

Yang, X., Fan, C., Shang, C., \& Zhao, Q. (2010). Nitrogenous disinfection byproducts formation and nitrogen origin exploration during chloramination of nitrogenous organic compounds. Water Research, 44(9), 2691-2702.

Yu, Y., \& Reckhow, D. A. (2015). Kinetic Analysis of Haloacetonitrile Stability in Drinking Waters. Environmental Science and Technology, 49(18), 11028-11036. 